\title{
Terrorismo y estereotipos de género ${ }^{1}$ Terrorism and gender stereotypes
}

\author{
Eulalia Pérez Sedeño \\ Instituto de Filosofía, CCHS-CSIC
}

Resumen. Las discusiones e investigaciones sobre el terrorismo raramente se centran en la implicación del género en la cuestión. La idea de que las mujeres sólo desempeñan, en todo caso, labores de apoyo, corresponde a unos estereotipos de género que asocian a las mujeres con la ternura, la compasión, la sensibilidad, el cariño, el cuidado, el afecto y la sumisión. Dichos estereotipos extienden la creencia de que las mujeres son apolíticas, que la división del trabajo entre mujeres y hombres se basa en diferencias físicas y en la distinta capacidad de unas y otros para llevar a cabo ciertos actos y en que el propósito y función primaria de una mujer es ser madre y esposa en vez de tener una identidad. Al aceptar esos estereotipos, las mujeres terroristas se convierten en una anomalía, en algo irracional, en especial las terroristas suicidas islamistas.

Palabras clave: terrorismo, estereotipos de género, mujeres terroristas suicidas.

\section{Introducción}

Cuando se plantea el papel de las mujeres en el terrorismo, lo primero en que se piensa es en las mujeres como víctimas, como individuos humillados por razones políticas o religiosas. Hay casos en diversas partes del mundo como Ruanda, Argelia, Yugoslavia y Afganistán, donde se han producido ataques sistemáticos
Abstract. Research and discussions on terrorism rarely take up the issue of gender. The idea that women only hold a supportive role in the terrorism, at most, reflects certain gender stereotypes which associate women with tenderness, compassion, sensibility, love, submission, and care. These type of stereotypes construct and ideal of an apolitical women, in which the labor division is based upon biological differences (women are more able to do certain tasks than others), but in which the primary role of women is, in the end, become a mother and wife instead of developing an identity. In accepting the above mentioned stereotypes, women terrorist then become an anomaly, an irrational subject, especially women Islamic suicide bombers.

Key words: terrorism, gender stereotypes, women suicide bombers.

contra niñas y mujeres. En las últimas décadas, por ejemplo, en Bosnia los grupos nacionalistas serbios ejecutaron una campaña sistemática de violaciones como parte de la limpieza étnica de la población musulmana de la región. Del mismo modo, en la provincia de Kivu, en el Congo, y en la región de Darfur, en Sudán, las mujeres han sido objeto de violaciones sistemáticas por parte de in- 
surgencias o contrainsurgencias de un tipo u otro. En Uganda, el Ejército de Resistencia del Señor (LRA, Lord's Resistance Army) despliega una política de rapto y reclutamiento obligatorio de chicas y chicos jóvenes para convertirlos en esclavas a las primeras y en soldados a los segundos. Y en Afganistán las chicas son envenenadas y se vuelan sus escuelas porque los talibanes creen que educar a las mujeres viola sus principios religiosos fundamentales ${ }^{2}$. Más allá de la vergüenza y la humillación, el propósito político detrás de estas campañas es extender el miedo y el terror entre el grupo objetivo, hombres y mujeres, una exhibición de dominio.

Pero la idea de que las mujeres son siempre víctimas, nunca las terroristas, es un estereotipo de género clásico en sí mismo. Además, en un nivel más básico, los esfuerzos antiterroristas no pueden ser efectivos si se basan en supuestos falsos sobre quiénes son los terroristas, por lo que hacer definiciones del terrorismo basándonos en que los terroristas son varones masculiniza el enfoque del terrorismo e introduce la peligrosa y destructiva idea de que estamos en «guerra» con el terror ${ }^{3}$.

\section{Un poco de historia}

El 30 de julio de 1977, Susanne Albrecht, una joven perteneciente al RAF (Rote Armee Fraktion, Facción del Ejército Rojo $^{4}$ ) tocó el timbre de la casa de su abuelo, Jürgen Ponto, director ejecutivo del Dresdner Bank y, cuando éste le abrió la puerta y Susanne le entregó un ramo de rosas, otro miembro de la banda le disparó, en un intento frustrado de secuestro.

Los titulares de los periódicos alemanes mostraban de manera clara el shock producido. El 1 de agosto de 1977, el periódico Bild decía: «La muerte llega con rosas rojas»; Stern encabezaba un reportaje publicado el 4 de agosto de 1977 con la frase que había dicho el abuelo al abrir la puerta: «Es Susanne»; otro medio de comunicación, Spiegel, titulaba un reportaje publicado una semana más tarde de la siguiente manera: "Las mujeres dominan ahora la escena terrorista en Alemania Occidental» y más adelante manifestaba que los criminólogos estaban confundidos y confusos acerca de los motivos que llevaban a una mujer a militar en organizaciones terroristas. No entendían cómo una joven agraciada y de clase media había echado por tierra todo lo que la sociedad esperaba de ella. La misma publicación insistía en que las mujeres y las jóvenes se estaban alejando de forma radical de sus roles convencionales, afirmando que las acciones de Albrecht «no encajan con la imagen tradicional del sexo que en inglés se denomina «the fair sex» (el bello sexo) - el género de la belleza, de la decencia, de la luz» (citado en Colvin, 2009, p. 193). La apelación a los sentimientos, a la belleza, la decencia, y la luz, como el encanto y el deber de la mujer, revela un cierto desamparo, o confusión cultural: si belleza y bondad no son equiparables y si la feminidad es algo que ya no podemos idealizar como pura y bella, ¿a dónde vamos a llegar?

¿Por qué tanta extrañeza? Lo que impactaba profundamente en la sociedad alemana era la «violación» de la tradicional subordinación de las mujeres y el estereotipo que las iguala con la naturaleza, la crianza, el cuidado y les asigna un carácter pasivo, emotivo y subjetivo; dicho de otro modo, en los grupos terroristas parecía haber una «división del trabajo» que no encajaba con la división tradicional, pues las mujeres no sólo ejercían tareas de ayuda, o recogida de información, sino que también eran luchadoras activas y hasta asumían labores de liderazgo. 
La historia ofrece ejemplos diversos de las implicaciones de las mujeres en actividades terroristas. Por ejemplo, las mujeres desempeñaron papeles importantes, incluyendo los de liderazgo, en el terrorismo que surgió en Rusia durante la década de 1870, mucho antes de que lograran el derecho al voto en las democracias occidentales. La primera organización terrorista moderna «La Voluntad del Pueblo» (Narodnaya Volya) surgió entre estudiantes jóvenes de clase media, incluyendo mujeres, que buscaban utilizar a los campesinos rusos para sus fines revolucionarios. Este grupo no pretendía llevar a cabo una revolución de masas, sino una serie de asesinatos selectivos, en concreto de líderes clave del régimen zarista. Entre 1878 y 1882 desplegó una campaña en este sentido que culminó con el asesinato del zar Alejandro II, en 1881. En sus memorias, Vera Figner, miembro del Comité Ejecutivo de La Voluntad del Pueblo da cuenta de estos hechos en los que participó ${ }^{5}$. Pero no fue la única mujer que participó en la muerte del zar, pues otras muchas estuvieron implicadas en la planificación y ejecución del asesinato, por el que fueron juzgadas y ejecutadas. A pesar de su derrota por parte de las autoridades rusas, La Voluntad del Pueblo sirvió de inspiración para otros grupos europeos, por ejemplo en Irlanda, y en otros no europeos (Weinberg y Eubank, 2011).

También las mujeres participaron en el Partido Socialista Revolucionario, que se formó en Kharkov en 1901 para eliminar la monarquía rusa y sustituirla por una República de obreros. De inspiración marxista (aunque ni Marx ni Engels estaban a favor del terrorismo individual) el partido creó una unidad separada, la Organización de Combate, para llevar a cabo operaciones terroristas que produjo una ola de asesinatos desde su formación hasta el estallido de la revolución en
1917. Dora Brilliant fue la encargada de idear el asesinato del ministro del interior en 1903, uno de sus logros más notables. Y pocas personas recuerdan que fue una mujer, Fanny Kaplan, miembro del partido revolucionario socialista antibolchevique, la que casi tiene éxito en asesinar a Lenin en 1918, pues consideraba que Lenin estaba dirigiendo mal el curso de la revolución.

Las mujeres tomaron más o menos parte en las luchas por la independencia de diversos países tras la Segunda Guerra Mundial, que tenían ciertos componentes terroristas, aunque en China, Sudeste Asiático, Cuba y África Subsahariana, la lucha armada predominante fue la guerra de guerrillas. En Argelia, en cambio, la lucha por su independencia de Francia, entre 1954 y 1962, incluía guerrillas rurales y actos terroristas urbanos; el Frente de Liberación Nacional (FLN) asignó la ejecución de importantes atentados terroristas a mujeres, sobre todo a aquéllas que podían pasar por europeas. Por ejemplo, «Zohra Drif, Dajmila Bouhard y Samia Lakhdari fueron a un mitin de Yacef [Saiidi Yacef, líder del FLN en Argel] en uno de sus escondites de la Casbah. Se les dijo que esa misma tarde iban a colocar tres bombas en el corazón del Argel europeo... Se quitaron el velo, se tiñeron el cabello y se vistieron con el tipo de ropa de verano floja que las muchachas pied noir llevarían para un día de playa. A cada una de ellas se les dio una pequeña bomba... Las mujeres pasaron luego por los controles del ejército francés en el barrio europeo. Dejaron sus bombas en diferentes lugares, incluyendo una cafetería - murieron tres personas y hubo docenas de heridos» (Weinberg y Eubank, 2011, pp. 26-27).

Los años sesenta vieron nacer o desarrollarse diversas organizaciones terroristas en Alemania (por ejemplo, el ya mencionado RAF), los Estados Unidos 
(como el Ejército Simbiótico de Liberación que saltó a la fama por el secuestro de Patricia Hearst y su posterior captación para la causa) y Sudamérica (como los Tupamaros uruguayos, los argentinos Montoneros o la peruana Sendero Luminoso) en las que las mujeres desempeñaron destacados papeles.

Finalmente, desde la década de los años ochenta en adelante se desarrolla un nuevo terrorismo con ciertos rasgos distintivos: en primer lugar, la religión desempeña un papel importante en la activación de los nuevos grupos; en segundo, no sólo le interesa matar cuanta más gente mejor, sino que mucha gente lo vea; en tercero, persigue la obtención de armas «de destrucción masiva» y la utilización de terroristas suicidas; y, por último, este nuevo terrorismo utiliza de forma amplia y masiva, las nuevas formas de comunicación disponibles en Internet (Weinberg y Eubank, 2011).

\section{Estereotipos de género}

Los estereotipos, esto es, el conjunto de creencias existentes sobre las características que se consideran apropiadas para hombres y para mujeres, sitúan a éstas en la esfera privada y al cuidado del hogar y de la descendencia, mientras el varón ocupa la esfera pública. Los rasgos estereotípicos de personalidad asociados a las mujeres las consideran tiernas, compasivas, sensibles a las necesidades, cariñosas, afectuosas, sumisas y de llanto fácil; en cambio, los que se asocian a la masculinidad atribuyen a los hombres comportamiento de líderes, que son amantes del peligro, individualistas, agresivos, de fuerte personalidad, atléticos, egoístas y duros (López-Sáez, Morales y Lisbona, 2008). Como se puede apreciar, rasgos muy acordes con lo que debe ser un auténtico terrorista y de los que carecerían las mujeres. Los mismos estereotipos se revelan en los comentarios de los líderes militantes que discuten el papel de las mujeres en los conflictos y que conducen a la perpetuación de ese mito y se traduce en la creencia, en primer lugar, de que las mujeres son apolíticas; en segundo, que la división del trabajo entre mujeres y hombres se basa en diferencias físicas y en la capacidad de unas y otros para llevar a cabo ciertos actos; $y$, en tercer lugar, que el propósito y función primaria de una mujer es ser madre y esposa en vez de tener una identidad. Los mismos, por ejemplo, aparecen en la organización terrorista ETA: en los funerales de activistas, la madre o la compañera oficia como símbolo de fertilidad, de la vida, la semilla de futuros luchadores: "la indarra (fuerza) se expresa de diferente manera en el hombre y en la mujer; así la indarra masculina se manifiesta culturalmente a través de la acción... Por el contrario, la indarra femenina se expresa fundamentalmente en el estar, el contener, el apoyar, lo que puede verse en el ritual funerario, donde es la mujer quien tiene el papel de asumir una situación dolorosa» (Aretxaga, 1988, citada en Alcedo, 1998, p. 64). Es decir, la mujer se mantiene en su papel tradicional, como guardiana de la etxe (casa) y representación de la tierra y de los poderes fecundos.

Los mismos estereotipos de género se encuentran en la base de la «sabiduría convencional» que, si bien tiende a ignorar el papel de las mujeres como actores centrales, tiene pocas dudas acerca de que las mujeres desempeñan roles de apoyo en favor de los grupos terroristas, pues se supone que las mujeres están en mejor posición para proporcionar y mantener casas seguras, para servir de cebo o efectuar labores de vigilancia o mensajería, porque por lo general levantan menos sospechas. Así sucedió, por ejemplo, en los inicios de ETA, donde comenza- 
ron a colaborar en infraestructuras, pero quedando al margen de lo más importante en la organización, la ekinza, la acción.

La creencia de que las mujeres sólo desempeñan esos papeles de apoyo y que no son actores principales en la planificación y ejecución de ataques terroristas se basa en estereotipos de género que buscan separar a las mujeres del conflicto, sea éste guerra o sea terrorismo, y mantener la posición de las mujeres como custodias de la vida civil. Los ejemplos son amplios y variados. En 2002, Shaykh Ahman Yassin, el líder espiritual de Hamás, ahora fallecido, hablaba en contra de la terrorista suicida Wafa Idris, no porque no le gustara la táctica, sino porque la había llevado a cabo una mujer: «la mujer es la segunda línea de defensa en la resistencia a la ocupación, protege a los fugitivos, pierde al hijo, al marido y al hermano, carga con las consecuencias de todo esto y se enfrenta a la hambruna y al bloqueo»» (citado en Herman, 2009, p. 5). Así pues, el papel de las mujeres es aguantar lo más duro del conflicto, mientras deja la primera línea a los hombres. Pero estas ideas no son sólo propias del mundo musulmán y su religión. El libro sobre la guerra de guerrillas del Che Guevara también afirmaba: «Pero también en esta etapa... una mujer puede efectuar sus tareas habituales en tiempo de paz... es más fácil mantenerla en sus tareas domésticas... los hombres menosprecian [esos deberes] que efectúan; ellas tratan constantemente de dejar de hacer esas tareas para entrar en las fuerzas que combaten activamente» (citado en Hermann, 2009 , p. 6) ${ }^{6}$.

Todo lo que se aleja del estereotipo se convierte en anómalo e irracional. Dolores González Katarain, Yoyes, reflexionaba al respecto, aunque desde una perspectiva más feminista: «No quiero convertirme en la mujer que, porque los hombres consideran de alguna forma macho, es aceptada. Cómo lograr que mi presencia signifique de hecho que otras también puedan estar, cómo lograr que mi presencia llame a otras y no tienda a considerarme, de alguna forma, un bicho raro, cómo lograr que estos hombres comprendan que la liberación de la mujer es un objetivo revolucionario para que lo asuman plenamente» (González Katarain, 2009, p. 57). En otro escenario, uno de los titulares de Spiegel poco después del asesinato de Ponto por el FAR, rezaba de la siguiente manera: «las mujeres en los grupos clandestinos: algo irracional». Citando a un ex jefe del Verfassungsschutz federal, Günter Nollau, el artículo desarrollaba toda una serie de tópicos que igualaban lo femenino con lo irracional, haciéndose eco así de los estereotipos dicotómicos y jerárquicos que equiparan lo femenino con lo irracional, la emotividad, subjetividad, la naturaleza, etc., y lo masculino con lo racional, objetividad, la cultura, etc. Según este «experto», las mujeres alemanas estaban cometiendo en esos momentos más de la mitad de todos los actos de violencia terrorista. El diagnóstico que recoge Spiegel es el siguiente: «la emancipación de las mujeres ha llegado al exceso» (Colvin, 2009, p. 195). El resultado es el ascenso de la irracionalidad; el caos, el colapso de la razón se presenta cuando desaparece el dominio masculino, su racionalidad, que justifica que los hombres estén al mando porque piensan mejor. Uno de los casos paradigmáticos, dentro del terrorismo de ETA, es el de Idoia López Riaño, apodada «la Tigresa», que es descrita como alocada, temperamental, mal disciplinada, «esclava de su cuerpo y su cabello»y «terrenal» ${ }^{7}$.

Los estereotipos sexistas que rodean a las terroristas hacen que las mujeres implicadas en violencia terrorista sean 
más demonizadas que los hombres. El supuesto habitual es que las mujeres terroristas deben estar incluso más deprimidas, más locas, ser más suicidas, psicópatas que sus contrapartes masculinas. En palabras del periodista José Luis Martín Prieto, «la crueldad de las mujeres supera a la de los hombres. Son capaces de alcanzar territorios despiadados, inexplorados por los varones» (Antolín, 2002, p. 21). Y abundando en el estereotipo esencialista femenino añade. «La mujer, que genera la vida, también puede alcanzar la mayor capacidad para quitarla» (ibidem). Alcedo (1998) señala: «Según los testimonios de los varones los militantes más "sanguinarios" (sic) son mujeres». Pero, seguramente, es el pago por su integración en las organizaciones terroristas, es resultado de la presión que se ejerce sobre ellas. Como señala Alcedo, cuando la mujer no se resigna a ese papel subordinado y pasivo y «reclama poder efectivo buscando ella también los que tradicionalmente han sido elementos de simbolización de la indarra masculina... empieza a imitar los aspectos más llamativos y tal vez más burdos de la conducta masculina... comienza a hacerse familiar la presencia femenina en los actos más espectaculares de la organización... A medida que la mujer coge el hierro y, sobre todo, en la medida en que muere por el hierro, se observa en los comentarios de mis informantes varones una mayor aceptación de la mujer en la organización. La integración se paga en sangre» (Alcedo, 1998, pp. 6-7).

Con respecto al acto terrorista llevado a cabo por el RAF, antes mencionado, el editor de Die Welt se quejaba a los lectores de que las mujeres terroristas demostraban un maligno potencial de emancipación: «[hay] una nefasta influencia de una determinada raza del feminismo. Las mujeres de los círculos revolucionarios están constantemente bajo presión para probar a los demás, pero sobre todo a sí mismas que están "emancipadas" y "son tan buenas como los hombres". No sólo están en guerra contra el enemigo de clase si no contra su propia naturaleza interna. Eso hace que sean todavía más desesperadas y violentas; hace que sean horrorosamente duras de corazón y despiadadas $\gg{ }^{8}$. Ésta es otra idea también muy extendida, otro estereotipo, a saber que cuando las mujeres se dedican a la violencia son peores que los hombres. También la Tigresa es descrita como mortífera, sanguinaria, indomable, «una serpiente venenosa», una «dama negra» (Antolín, 2002, pp. 20-21).

\section{Las terroristas suicidas y los estereotipos de género}

En el análisis del terrorismo ejecutado por mujeres se presentan una serie de cuestiones que no se han planteado de manera explícita hasta muy recientemente: ¿cuál es el papel de las mujeres en el terrorismo? ¿Son víctimas - directas o colaterales - o agentes? Y, en este caso, ¿ejercen tareas de apoyo o desempeñan papeles activos en la organización y ejecución de atentados? Y si esto es así, ¿por qué o cuáles son sus motivos? ¿Son diferentes a los de los varones? Dicho de otro modo, ¿tiene género el terrorismo? ¿Es el terrorismo un medio «masculino» que cada vez usan más las mujeres islámicas para plantear su bajo estatuto en la sociedad y lograr la liberación? ¿Lo usan las mujeres porque «sólo con el arma del símbolo clásico de la masculinidad y con particular crueldad [una mujer islámica puede lograr] ser una mujer completamente emancipada»? ¿O el terrorismo es simplemente un acto de guerra «unisex» que es usado por las mujeres? Cuando una mujer lleva a cabo una misión suicida ¿lo hace como fundamentalista islámica, en el nombre de la liberación del 
Islam, o lo está haciendo como una feminista oprimida en el nombre de la emancipación de las mujeres?

Examinaremos brevemente algunos casos de mujeres islámicas suicidas, usando fundamentalmente mujeres palestinas y sus patrones de casos individuales, para analizar el impacto de las cuestiones de género en el contexto del terrorismo islámico. Esos patrones muestran que las mujeres que toman parte en actividades terroristas, a diferencia de la mayoría de sus contrapartidas masculinas, no estaban guiadas puramente por motivaciones de liberación del Islam y toman en consideración factores adicionales, tales como las circunstancias personales que las dejaron sin nada que perder o con sed de venganza.

La importancia de las terroristas suicidas radica en el auge experimentado en los últimos años. Entre 1985 y 2010 las terroristas suicidas cometieron unos 260 ataques con bombas (aproximadamente una cuarta parte de todos los perpetrados) desde diferentes organizaciones terroristas. Desde 2002, en algunos países suponen el $50 \%$ de los operativos, habiendo matado o herido a cientos de personas, hombres, mujeres y niños (Bloom, 2011).

Como hemos visto, los estereotipos de género supuestamente «alejan» a las mujeres del terror y se considera que las terroristas son una anomalía, una excepción. En este sentido se tiende a buscar razones: en qué entorno familiar han crecido y en qué medida y cómo fueron socializadas. Debido a los estereotipos de género parece «innatural» que las mujeres sean capaces de ejercer la violencia y se recurre a maldecir al cruel padre, marido, hermano u otros parientes masculinos, que la obligaron por primera vez. Pero, es un mito suponer que las mujeres son pacíficas y que estas mujeres que cometen ataques suicidas son una excep- ción a la regla. Siempre han existido y la idea de que una mujer que actúa de forma inhumana no lo hace por propia voluntad es absurda. Las terroristas suicidas prueban lo opuesto y rompen con ello un tabú en dos niveles: no sólo violan la norma del ser humano civilizado, sino que, además, sacuden los fundamentos de la imagen idealizada de la mujer dentro del Islam.

Hay varios ejemplos de mujeres «mártires» en la historia del Islam. La más conocida y prominente sea probablemente Nusayaba bint K'ab, que según la leyenda luchó al lado de su marido y sus dos hijos en el califato de Abu Bakr en el siglo VII. Fue herida 11 veces y perdió un brazo. También se ha dicho que varias mujeres parientes del profeta Mahoma, como su esposa Aisha y su nieta Zaynab bint Ali, fueron activas en la Jihad. Sin embargo no se utilizan estas figuras históricas como modelos de referencia, sino otros de la historia más reciente, como Loula Abboud o Wafra Idris. Loula fue la primera mujer que se voló a sí misma en Oriente Medio, en abril de 1985, después de que los soldados israelíes actuaran contra su grupo. Su historia fue notable porque era cristiana y comunista y por lo tanto no entraba en el perfil usual de la suicida islámica con bomba. Wafa Idris se convirtió en una heroína palestina y un modelo de referencia en el año 2002, al ser la primera mujer palestina que llevó a cabo un ataque suicida en Israel. Un periódico egipcio incluso la describió como «la novia del cielo, que prefirió la muerte a las diversiones de la vida» $\mathrm{y}$ consideró que era un «potente mensaje para la nación árabe».

El famoso caso de Wafa Idris rompió el mito de las mujeres pacíficas. Incluso aunque en muchos casos se considera que estas mujeres son víctimas, en la percepción del público se convierten en modelos de referencia. Wafa Idris, 
por ejemplo, se convirtió en un icono generacional, pues hasta entonces, en los territorios palestinos ocupados, las mujeres habían sido utilizadas como carne de cañón. Otro icono del terrorismo internacional moderno en Oriente Medio, Leila Kahled, que en los años 70 estuvo implicada en el secuestro de un avión en nombre del Frente de Liberación Palestina, se convirtió en la pinup girl del terrorismo para la gente de la calle e inspiró a cientos de mujeres jóvenes del mundo que admiraban sus famosas y emocionantes imágenes en los medios ${ }^{9}$. Y la idea de la madre sacrificada que no es capaz de matar a otra persona llegó a su final con el ataque perpetrado por Reem Reyashi, madre de dos niños, que hizo estallar su bomba suicida en un control matándose a sí misma y a cuatro israelíes ${ }^{10}$.

Pero la aceptación social y política de estas mujeres dista de ser unánime. Osama Bin Laden expresó claramente en su famosa fatwa de 1996 «la declaración de guerra contra los Estados Unidos y occidente» y además afirmó que las mujeres juegan un papel importante en la Jihad: «nuestras mujeres... motivan y consuelan a sus hijos, hermanos y esposos para luchar contra el enemigo» ${ }^{11}$. Interesantemente el papel de las mujeres quedó fuera en su siguiente fatwa de 1998, «La Jihad contra judíos y cruzados». En la Hamás palestina inicialmente su líder, Sheik Yassin, rechazó que las mujeres fueran bombas vivientes. El éxito de esta estrategia en la Hisbollah libanesa, las brigadas Al-Aqsa y la Jihad islámica palestina le persuadieron de usar a las mujeres como «un ejército de reserva» que pudiera ser usado, si fuera necesario, y que luego fue implementado.

Tanto Hamás como la Jihad islámica al comienzo de la primera Intifada señalaron que no permitirían que se reclutara a mujeres. Tiempo después el líder de la Organización para la Liberación de $\mathrm{Pa}$ - lestina, Yasser Arafat, apeló a la igualdad: «las mujeres y los hombres son iguales. Vosotras sois mi ejército de rosas que destruirán los tanques israelíes» (Victor, 2003). La tarde del 27 de enero de 2002, el mismo día en que Arafat hizo esa declaración, la ya mencionada, Wafa Idris, se voló a sí misma en un centro comercial de Jerusalén. Un ataque suicida y un mes más tarde, el líder espiritual de Hamas promulgó una fatwa que admitía el derecho de las mujeres a engrandecerse a sí mismas y alcanzar el paraíso mediante ataques terroristas suicidas.

Hay otras diferencias de género entre los terroristas hombres y mujeres. La demanda de terroristas varones es mucho mayor que la de terroristas mujeres, pues las organizaciones están menos abiertas a reclutar mujeres. Esto significa que un terrorista varón dispone de una amplia variedad de organizaciones donde elegir a la hora de desarrollar sus actividades terroristas, mientras que una mujer podría incorporarse a una organización terrorista que no represente completamente sus ideas e ideales porque no hay otra que la acoja. Además, mientras hay muchos campos de entrenamiento para terroristas varones, sólo hay un campo de entrenamiento conocido para mujeres terroristas (financiado por la organización terrorista femenina las Brigadas de $\mathrm{Al}$ Aqsa), lo que significa que las mujeres que deciden enrolarse en actividades terroristas están menos entrenadas y tienen menos experiencia.

En las sociedades islámicas se enseña que llevar a cabo una misión suicida conduce directamente al cielo, sea quien fuere quien ejecute la acción. Pero el reconocimiento que se les da a mujeres y hombres con respecto a sus actividades terroristas también es diferente. En este mundo las mujeres no son tratadas de igual manera, pues si bien se supone que tanto unas como otros, como mártires, 
irán al paraíso, el tratamiento en la tierra es diferente, alcanzando ellos un estatus de estrella, con sus retratos colgados en los muros, etc. Tampoco son tratados de igual manera por lo que se refiere a la paga compensatoria que da Hamás, la Jihad islámica o la Autoridad Nacional de Palestina por llevar a cabo misiones suicidas. Según Barbara Victor (2003) mientras las familias de los suicidas varones reciben una pensión durante el resto de su vida de unos $400 \$$ al mes, las familias de las terroristas suicidas raras veces reciben la mitad de esa cantidad.

Los ataques suicidas son eficientes con respecto al coste, tecnológicamente fáciles de llevar a cabo y con bajo riesgo. Las terroristas a menudo son más mortales por el elemento sorpresa. Las terroristas suicidas con bombas tienden a ser más exitosas en alcanzar sus objetivos y tienen proporciones más altas de asesinatos que los hombres. Por media matan cuatro veces más personas que sus contrapartes masculinas. Las mujeres parecen menos sospechosas y son controladas de manera menos estricta por las fuerzas de seguridad. Se convierten en armas baratas. Además de esta ventaja táctica hay otras muchas ventajas estratégicas, ya que los ataques realizados por mujeres atraen muchísimo el interés de los medios (en una proporción de ocho a uno con respecto a los hombres), uno de los objetivos diferenciadores de este terrorismo de última hornada. Así se logra mejor la expansión del miedo y el horror y las ambiciones políticas. Las mujeres sirven además porque inspiran simpatía; los medios de comunicación se interesan más por sus motivaciones, su situación familiar y personal. Un cálculo esencial que hay detrás de las operaciones suicidas de las mujeres es la efectividad en los medios. Le va bien al negocio de los medios el horror y lo inimaginable que resultan las terroristas suicidas, especial- mente en occidente. Normalmente no se espera que una mujer sea capaz de una acción tan «inhumana». Eso se sigue de los estereotipos antes mencionados. Por eso se produce esa sensación de espanto y de estupefacción. Si la suicida está embarazada o deja huérfanos y marido eso representa un paso más en el camino psicológico de la incomprensión y el horror. Como efecto colateral, la captación de terroristas suicidas también aumenta el reclutamiento de los hombres debido a la vergüenza de que las mujeres actúen y ellos no.

Según el jeque Yussef al-Qaradwi, las terroristas suicidas son «héroes de nuestro tiempo que se sacrifican por el Islam como bombas vivas» ${ }^{12}$. El hecho es que dicho jeque apoya los comandos suicidas palestinos desde 1995. Sus seguidoras femeninas le aprecian principalmente porque él defiende la «emancipación» de las mujeres, en la misma medida que elogia a las terroristas suicidas femeninas. Para las mujeres que son menos valientes, aunque ellas están listas para el combate, sugiere la Jihad económica, es decir, la guerra santa de los boicots, como no comprar Coca-Cola, McDonald o pañales desechables de marcas occidentales $^{13}$.

La cuestión de por qué las mujeres palestinas se convierten en terroristas suicidas ha preocupado a mucha gente. Se han realizado simposios y conferencias y se han escrito muchos artículos periodísticos y académicos sobre este fenómeno. El caso de Wafa Idris, de 27 años, se presenta menos como un acto político que como un intento de evasión de una mujer marginada que se divorció porque no pudo tener hijos durante los nueve años que duró su matrimonio. Además tenía mala relación con su hermano mayor, que desde la muerte del padre se convirtió en el hombre dominante de su vida. En la sociedad palesti- 
na tradicional, una divorciada sin hijos es una carga y no tienen la posibilidad de volverse a casar. Este tipo de mujeres, que no se ajustan a las normas sociales, son muy fáciles de captar. Wafa Idris, la primera terrorista suicida palestina en Israel, sirve como figura a la vez que como ejemplo de las mujeres reprimidas en la sociedad masculina islámica. Ella asesinó para recuperar su honor perdido en la sociedad islámica.

Éste es el tipo de respuestas que se da a la cuestión de por qué las mujeres se conviertan en terroristas $\mathrm{y}$, por lo general, están sesgadas. Se supone que el género «débil y blando» se une principalmente a la Jihad militante debido a razones sociales y emocionales tales como la filiación familiar, la muerte del marido, divorcio o sólo ingenuidad. Wafa no podía tener hijos y su marido se divorció de ella. Como mujer sin hijos, está fuera de la sociedad y rescató su honor y el de su familia eligiendo la «muerte de una mártir». Pero no hay un perfil comprehensivo de las terroristas suicidas. Las motivaciones, los hechos concomitantes y las historias personales son demasiado dispersas. La mujer iraquí y su marido que intentaron volarse en el hotel Radisson de Ammán pretendían aparentemente vengarse de la muerte de sus hermanos a manos del ejército de los Estados Unidos. Muchas mujeres chechenas se vengan de las violaciones en masa por parte de los soldados rusos. En las Tigresas de Tamil la tortura y el abuso sexual jugaron un papel enorme. En Palestina un «mártir» se convierte en héroe, como hemos dicho, su imagen se pone en los muros. La valoración social de la familia aumenta en algunos casos e incluso reciben dinero que sirve para pagar la educación de los hermanos. También hay otra justificación, como la vida insostenible bajo la ocupación israelí, la discriminación y humillación por parte de los soldados israelíes que los mantienen encerrados entre muros sin poder ir a donde quieran, es decir, que están básicamente como en una prisión. En esta situación, la muerte y la vida eterna en el paraíso podrían parecer atractivas. Ciertamente se puede considerar como un tipo y «pseudo-acto» de emancipación, aunque no en el sentido de las mujeres occidentales. Por primera vez, las mujeres islámicas actúan por sí mismas sin pedir permiso a nadie. No sólo los hombres son guerreros orgullosos, también lo son las mujeres, lo que las iguala en un terreno dominado por los hombres. Esto prueba que el aspecto religioso no es necesariamente lo principal, especialmente en el caso de las mujeres. Sin embargo no se pueden evitar los aspectos religiosos a la hora de considerar a las mártires y sus motivaciones, ya que están profundamente enraizados en su vida religiosa y social.

En el caso de Sajida al-Rishawi, varios de sus hermanos habían sido asesinados en Irak en la lucha contra las tropas aliadas. Para los grupos de la Jihad ella era vulnerable para ser indoctrinada y movilizada después de sus muertes, aunque se presentó voluntaria para su misión en Jordania después de que un matrimonio de conveniencia le proporcionara una cobertura plausible para viajar. En el caso de Muriel Dagausque, una mujer belga convertida al islam que se voló en Irak, fue ella quien persuadió a su marido para unirse a la Jihad, desafiando su hombría y urgiéndole a proteger y defender a sus hermanas del islam. La manipulación de los roles tradicionales de género tiene también un poderoso efecto en las sensibilidades y sentimientos masculinos de obligación individual. La idea de que los hombres podrían estar ocultándose tras las faldas de las mujeres resuena en estas sociedades dominadas por los hombres. Las mujeres terroristas, 
por otro lado, retan a los hombres a ser más proactivos. Las organizaciones terroristas son conscientes de este influjo y utilizan de forma deliberada operativos femeninos para avergonzar a los hombres y hacerles participar y hacer más por la causa.

Algunos estudios han argumentado que las motivaciones de las terroristas suicidas son de tipo emocional, personal, y que sus motivaciones políticas están menos fundamentadas porque, en las entrevistas que les hacen inmediatamente después de su arresto, cuentan historias diferentes a las que relatan en entrevistas posteriores, después de un período en prisión, incluso aunque sea la misma persona quien realice ambas entrevistas. Se considera que esta inconsistencia en las narrativas de las mujeres es una prueba de que han adoptado un lenguaje político mientras estaban en la cárcel y que sus motivaciones «reales» son de hecho personales. Yoram Schweitzer (2006) señaló que cuando se les preguntaba inicialmente por las razones para cometer un ataque suicida, la mayoría de las suicidas palestinas, fracasadas, revelaban alguna «razón secreta» que tenía poca relación con la política o con la religión y que sin embargo tenía mucho que ver con una tragedia o vergüenza privada. A las pocas semanas de estar en prisión, las mujeres habían alterado sus historias, revelando en los posteriores interrogatorios razones muy politizadas. Schweitzer se fía de las afirmaciones iniciales de las mujeres sobre las razones personales para ser terroristas suicidas y cuestiona, en cambio, sus discursos políticos adquiridos después de un tiempo en la cárcel. Piensa que las mujeres reaccionan a la soledad, al rechazo o alguna imperfección que hace que convertirse en una mártir sea más atractivo que vivir. Convertirse en una terrorista suicida es preferible a un matrimonio concertado o a una vida tediosa con un hombre al que no se ama. Una adolescente se presentó voluntaria para ser terrorista suicida porque su padre no dejó que se casara con su novio. Otra estudiante universitaria dijo que prefería pasar su vida en una prisión israelí que atrapada con un marido al que no amara. Sin embargo esto puede ser cierto de las mujeres palestinas pero no sucede en otros casos. Por ejemplo, en entrevistas con las Tigresas de Liberación Tamil, el director noruego Beate Arnestad encontró que las mujeres terroristas de organizaciones nacionalistas no religiosas no consideraban que su género fuera importante y estaban tan dedicadas políticamente como los hombres. Lo mismo puede decirse de las mujeres de ETA (Hamilton, 2007).

La idea de que los hombres están más politizados y que las mujeres actúan por pasión, se funda nuevamente en estereotipos y no da cuenta del proceso de implicación en el terrorismo, en el que los hombres se movilizan en una proporción diferente y en diferentes momentos que las mujeres. Alegar que las mujeres son histéricas o emocionales, mientras que los hombres planean fría y racionalmente los ataques, se basa en un supuesto inherentemente sexista, a saber, que las mujeres se comprometen menos que los hombres. Mientras es casi imposible desagregar motivaciones complejas y que se solapan, la atención que los medios de comunicación pone en las historias personales de las mujeres ha hecho que mucha gente asuma que ése es el caso.

Por un lado, esa idea va en contra de las descripciones que muchos terroristas varones hacen de sus experiencias. Un número importante de terroristas varones tienen diferentes historias infantiles de humillación, angustia, pena, ira, que les hizo involucrarse en esos movimientos. Eso significa que tanto hombres como 
mujeres experimentan o tienen razones personales para unirse a los movimientos terroristas. Este motivo personal inicial cambia según el terrorista varón se ve involucrado más profundamente en el movimiento y se profesionaliza, en cierto modo.

Pero las mujeres son movilizadas de manera diferente y están sometidas a constricciones de las sociedades en las que viven. Mientras niños y niñas pueden realizar por igual actos de resistencia, como tirar piedras, según todos ellos se hacen mayores sus caminos divergen y a las chicas se las aísla cada vez más, pues las normas sociales limitan la integración con hombres con los que no estén emparentadas. Según los chicos se van haciendo mayores pasan de tirar piedras a tirar bombas de gasolina. Pasan de desempeñar papeles de apoyo a otros más operativos, primero como vigilantes, luego llevando mensajes y, finalmente, pasando a las actividades de primera línea, que incluyen el terror suicida. Pero mientras los chicos van pasando a roles cada vez más activos, las chicas a menudo están relegadas en casa. Mientras los chicos participan en actividades clandestinas, las chicas son excluidas de las reuniones en las que se reúnen hombres y mujeres que no están emparentados. Durante este período de adoctrinamiento/profesionalización, los chicos aprenden el lenguaje de la política y la resistencia. Como grupo desarrollan fuertes vínculos con sus compañeros y cuando están al final de su adolescencia, pueden discutir con sofisticación sobre la historia y la política de la resistencia. Sin embargo, a las mujeres no se les permiten estas mismas oportunidades debido a los costes sociales de la propiedad sexual y el código del honor. Solamente una vez que las mujeres están involucradas en los movimientos terroristas, en gran medida debido a vínculos filiales, tienen acceso a otras mujeres que tienen ideas semejantes y que comparten su pasión. Ése es el caso de las mujeres, que una vez encarceladas, son capaces de dominar la historia y la política del movimiento (Bloom, 2011).

Así pues, las mujeres no pueden experimentar la movilización política en grandes grupos hasta que se encuentran detrás de las rejas. Hasta que no son encarceladas no pueden tener acceso a los marcos políticos de referencia que describen de manera precisa su implicación como motivada políticamente. Está probado que el tiempo que se pasa en prisión facilita el proceso de radicalización. Después de semanas o meses con otros miembros de Hamás o la Jihad islámica, no importa las motivaciones individuales que se pueda haber tenido, las prisioneras o prisioneros comienzan a usar la jerga de la Jihad y del nacionalismo en sus historias. La prisión no cambia las historias de las mujeres, proporciona el escenario para profundizar en su radicalización y articular sus sentimientos utilizando el lenguaje de la política. No hay motivos diferentes que diferencien la implicación de las mujeres y de los hombres en las actividades terroristas, sino las mismas series de motivaciones y experiencias que ocurren en diferentes tiempos durante el curso de sus vidas.

\section{Consideraciones finales}

A pesar de la fuerte presencia de las mujeres en las organizaciones terroristas islámicas, ni se debe ni se puede generalizar sobre las mujeres dentro de las organizaciones terroristas. Problemas personales como no tener hijos o estar soltera son a veces motivos, sin embargo, no existe un perfil claro, pues van desde solteras de 19 años hasta abuelas. Al final simplemente es una decisión estratégica de cada organización en qué medida mejoran las mujeres sus ataques. 
Organizaciones islámicas como la Jihad islámica y Hamás reclutan mujeres, aunque eso contradice fundamentalmente las normas religiosas y sociales tradicionales. La preparación de un acto terrorista requiere varias actividades en las que las mujeres tienen que estar en estrecho contacto con hombres con los que ni están casadas ni están emparentadas. Las mujeres son reclutadas en su mayor parte para operaciones con objetivos civiles, como la mujer de 29 años de edad, Hanani Jaradat, que se auto explotó en octubre de 2003 en el restaurante Maxim en Haifa matando a 19 personas. Durante el período de reclutamiento de las mujeres, tanto la Jihad islámica como Hamás reflejan las circunstancias personales de las candidatas y a veces les presentan la muerte por martirio como la solución más ventajosa en caso de una situación de conflicto privada, como un divorcio, intercambio sexual ilegítimo, infidelidad en el matrimonio, etc.

No existen indicaciones de que las mujeres participen en la jerarquía de la organización ni en posiciones relevantes. Las organizaciones terroristas implementan el terrorismo suicida femenino de una forma sistemática, que depende de la comunidad. Es importante señalar que la sociedad palestina conservadora y patriarcal de la franja occidental, por ejemplo, es más secular que la de los residentes en la Franja de Gaza, donde están en el poder la Jihad islámica y Hamás. En comparación con otras sociedades musulmanas, las mujeres palestinas parecen tener relativamente más oportunidades y libertad que las mujeres musulmanas de Irak, Irán, Arabia Saudita y otros países dominados por los hombres. A las mujeres palestinas se les permite votar, desempeñar un oficio, conducir coches y poseer propiedades (Beyler, 2003). Al estar relativamente más implicadas en ciertos aspectos de la vida, se convierten también en agentes activos en el terrorismo suicida. Las suicidas palestinas matan israelíes; ya no son sólo mujeres que mueren como mártires, sino que más bien alcanzan «la libertad personal» que antes no tenían.

Pero, sería no sólo cínico sino simplemente erróneo hablar de la emancipación de las mujeres dentro de la sociedad islámica. Muchos estudiosos musulmanes y feministas occidentales han discutido de manera apasionada acerca del estatuto de las mujeres musulmanas dentro del islam. Sin embargo ninguno de esos grupos ataca de la misma manera las cuestiones centrales que rodean los roles de género. Tanto el feminismo como el Islam tienen su propio reconocimiento de los derechos de las mujeres. El feminismo favorece la percepción del cambio social utilizando la ley, mientras que el Islam favorece una percepción social moldeadora de las mujeres que encaje con las regulaciones éticas del Islam y del Corán. Esta diferencia de mentalidad crea un conflicto, por el que el feminismo, que considera que el compromiso entre hombres y mujeres es liberador, se enfrenta con la idea islámica de que el aislamiento de las mujeres contribuye a su honor personal y al de su familia.

El feminismo favorece la comprensión y por tanto la redefinición de los roles y relaciones de género según determinadas sociedades. El islam, en cambio, tiene definiciones de rol de género rígidas que no están abiertas a la redefinición, ya que se consideran que son inflexibles pues se derivan del sexo biológico. En las sociedades islámicas cuidar de los niños y de la esfera doméstica en general se entiende que es una de las más importantes, si no la única, responsabilidad de una mujer. Esto no quiere decir que las mujeres musulmanas no puedan entrar en el mercado de trabajo. Sin embargo, el estatuto de la maternidad es tan valorado en las sociedades islámicas que 
supone un desafío a la idea de que los roles de género son creados socialmente en vez de biológicamente dados.

Las terroristas siempre serán definidas por su género dentro de la sociedad y de su organización terrorista; se convierten en armas en manos de los hombres y de la organización terrorista en vez de una parte esencial de la infraestructura. Como dijo Orna Sasson-Levy (2003, p. 451) «los hombres son lo militar, las mujeres están en lo militar». El terrorismo islámico tiene género, ya que las terroristas islámicas pretenden y tienen un significado indirectamente metafórico simbólico dentro de una sociedad dominada por los hombres donde las mujeres islámicas adoptan roles tradicionales masculinos para igualarse en la sociedad, a pesar de estar marcadas por los estereotipos femeninos de género.

\section{BIBLIOGRAFÍA}

Alcedo, Miren (1998): «Mujeres de ETA: la cuestión del género en la clandestinidad», La Factoría, n. ${ }^{\circ}$ 4, octubre-enero.

Antolín, Matías (2002): Mujeres de ETA. Piel de serpiente, Madrid, Temas de Hoy.

Beyler, Clara (2003): «Messengers of Death-Female Suicide Bombers», febrero (www.ict.org.il/apage/10728. php) page. 11 .

Bloom, Mia (2011): «Bombshells: Women and Terror», Gender Issues, 28, pp. 1-21.

Colvin, Sarah (2009): Ulrike Meinhof and West German Terrorism. Language, Violence and Identity, Rochester, Nueva York, Camdem House.
González Katarain, María Dolores (2009): Yoyes, desde su ventana, Arberdania.

Hamilton, Carrie (2007): Women and ETA. The Gender Politics of Radical Basque Nationalism, Manchester University Press.

Herman, Susan (2009): «Women and Terrorism», en The Gender Dimensions of Terrorism: How Terrorism Impacts the Lives of Women, Women's Rights Law Reporter 40th Anniversary Symposium. Rutgers Law School. Disponible en http:// www.aclu.org/gender-dimensions-terrorism-how-terrorism-impacts-liveswomen.

López-Sáez, Mercedes; Morales, J. Francisco y Lisbona, Ana (2008): «Evolution of Gender Stereotypes in Spain: Traits and Roles», The Spanish Journal of Psychology, Vol. 11, n. ${ }^{\circ} 2$, pp. 609-617.

Sanmartín, José (2005): El terrorista. Cómo es. Cómo se hace, Barcelona, Ed. Ariel.

Sasson-Levy, Orna (2003): «Feminism and Military Gender Practices: Israeli Women Soldiers in "Masculine" Roles», The Sociological Inquiry, 73 (3): 440-465.

Schweitzer, Yoram (2006): Female Suicide Bombers: Dying for Equality?, Jaffee Center for Strategic Studies, Universidad de Tel Aviv, http://www.inss.org.il/ upload/\%28FILE\%291188302013.pdf.

Victor, Barbara (2003): Army of Roses: Inside the World of Palestinian Women Suicide Bombers, Rodale.

Weinberg, Leonard y Eubank, William (2011): «Women's Involvement in Terrorism», Gender Issues, vol. 28, n. ${ }^{\text {os }} 1$ y 2, pp. 22-49. 


\section{NOTAS}

${ }^{1}$ Este trabajo ha sido posible en parte, gracias al proyecto del PN I+D+I, FFI 2009-07138-FISO.

2 Algo diferente es la violencia ejercida por ETA en nuestro país, donde de los aproximadamente 900 muertes, 38 mujeres han sido víctimas directas de la banda armada, aunque habría que añadir las que sufrieron la violencia en sus parejas, hijos o padres (Hamilton, 2007).

${ }^{3}$ Este último aspecto constituye una gran preocupación en los estudiosos del terrorismo (por ejemplo, Sanmartín, 2005).

4 También conocida como la «Banda BaaderMeinhof» (por el apellido de sus dos miembros más importantes y conocidos) fue una de las organizaciones revolucionarias de izquierda radical más activas de la República Federal de Alemania en la posguerra.

${ }^{5}$ Después del asesinato del zar, Vera fue arrestada y sentenciada a 25 años de prisión.

${ }^{6}$ Fidel Castro, en cambio, aceptaba la idea de que las mujeres entraran en combate, pero las consideraba una fuerza civilizadora: «incluso cuando las mujeres van por los montes con un rifle en la mano, siempre hacen que nuestros hombres sean más aseados, más decentes, más caballerosos» (Herman, 2009), es decir, siguen ejerciendo sus roles de género.

${ }^{7}$ En palabras de su compañero de organización terrorista, Suárez Gamboa, citado en El Mundo, 29 de julio de 2010.

${ }^{8}$ Günter Zehm en Die Welt (2 August 1977); citado en Colvin, 2009, 196. La cursiva es mía.

9 En las fotos aparece con chaqueta militar verde, un pañuelo palestino del que asoma un hermoso y generoso flequillo negro, a veces mirando recatadamente al suelo, a veces sonriendo, mientras acaricia una metralleta roja.

${ }^{10}$ Chris McGreal (15 January 2004). «Humanbomb mother kills four Israeli at Gaza checkpoint», The Guardian, http://www.fromoccupiedpalestine.org/ node/1054. Consultado del 8 de octubre de 2011. htm).

11 (http://nlarchiv.israel.de/2003_html/05/220503a.

12 (http://www.zeit.de/2002/37/Globalisierung auf_Islamisch).

${ }^{13}$ (http://nlarchiv.israel.de/2003_html/05/220503a. htm). 